\title{
GOLDEN EAGLES NEST SUCCESSFULLY IN TREES
}

C. STUART HOUSTON, 863 University Drive, Saskatoon, Saskatchewan, S7N 0J8 and KELWIN A. WYLIE, 43-24 Central Place, Saskatoon, Saskatchewan. S7N $2 \mathrm{~S} 2$

The Golden Eagle in Saskatchewan is typically a bird of the drier river valleys and "badlands." The overwhelming majority of pairs build their nests on steep clay banks of rivers and their tributary coulees. Between 1960 and 1984 Houston banded 107 young in 72 successful cliff nests. Even in northern Saskatchewan, Golden Eagle sites have been on rocky ledges, avoiding use of the universally prevalent trees. ${ }^{2}$

Twice, ranchers have taken us to an "eagle nest" in a tree on the plains but each time the birds proved to be Ferruginous Hawks. We have heard, after the event, of one seemingly authentic report of a pair of Golden Eagles nesting in a large cottonwood in the South Saskatchewan River Valley within $50 \mathrm{~km}$ of Leader. Edward Arnold also found a pair nesting in a willow in the McDonald Hills north of present Dysart in late June 1885. ${ }^{1}$

In 1977 the cliff-nesting pair near Riverhurst, after failing to produce young in 9 of 12 successive annual attempts, no doubt partly because of disturbance from fishermen's boats immediately below their traditional nesting site after the filling of Lake Diefenbaker, attempted to nest in a tree. A large new nest was built 22 feet from the ground in an introduc-

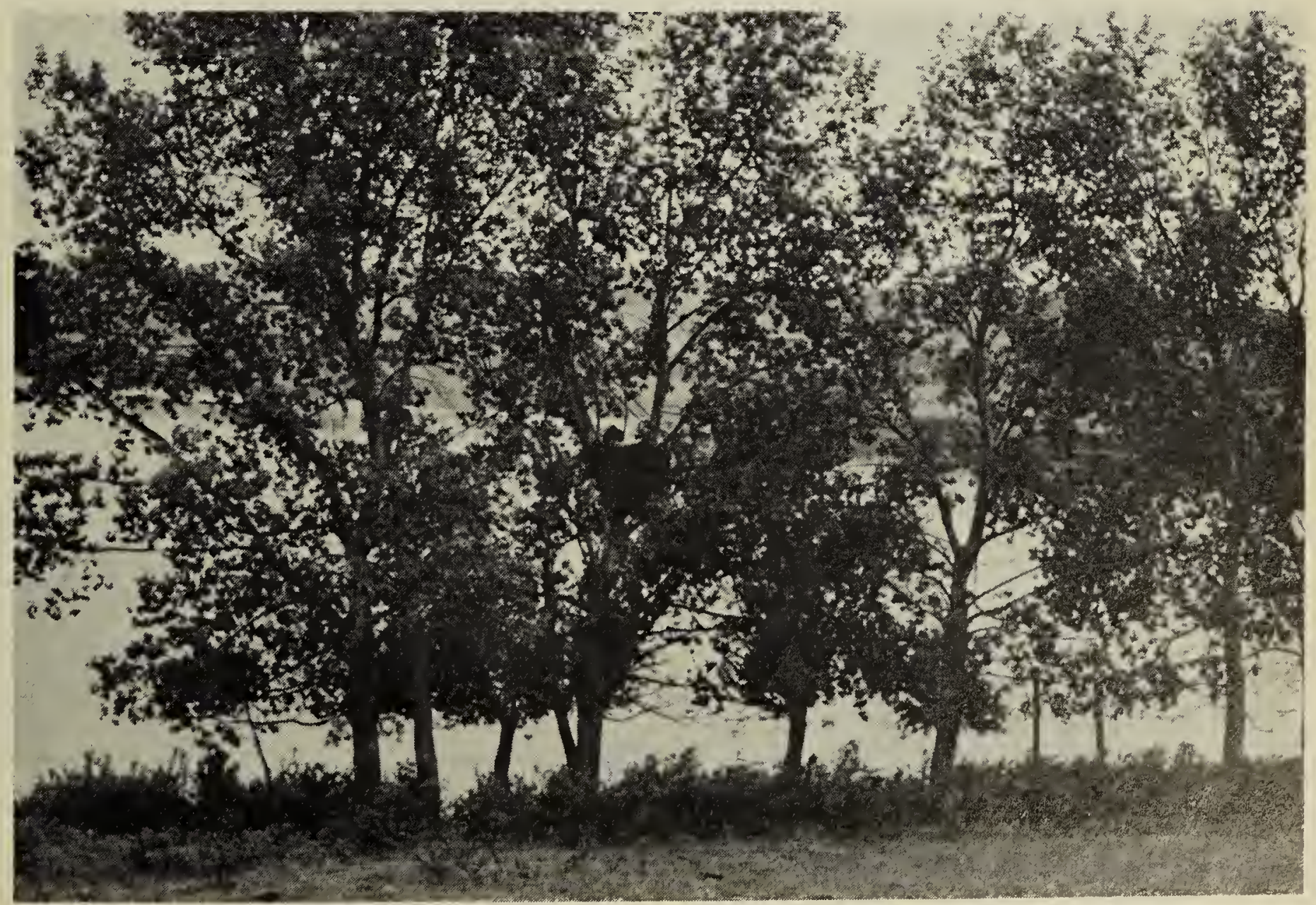




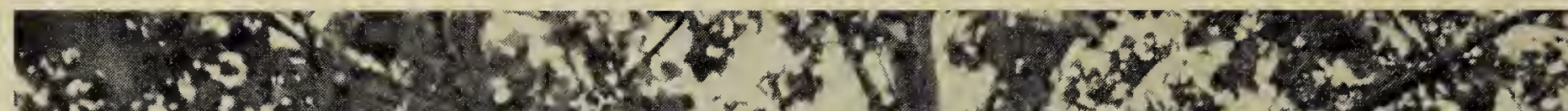

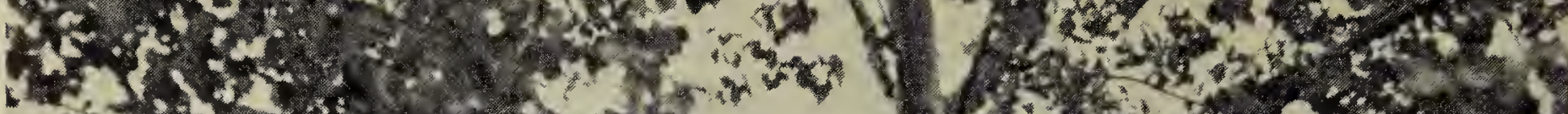

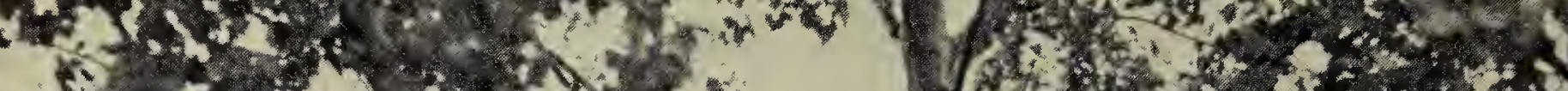

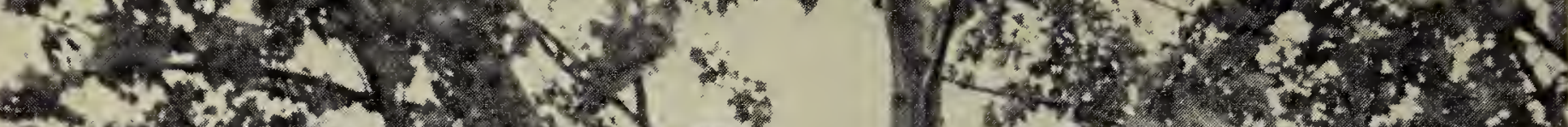
$2 x+2=0$ $x+\infty+a$

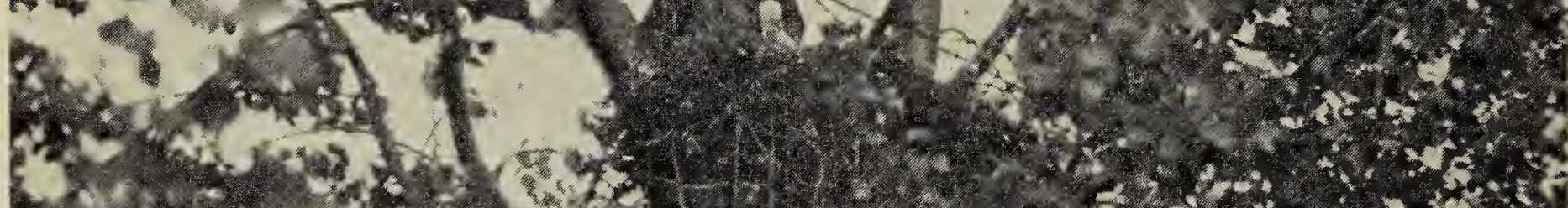

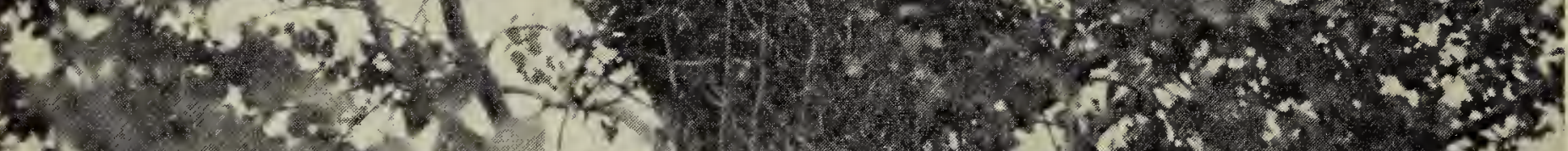

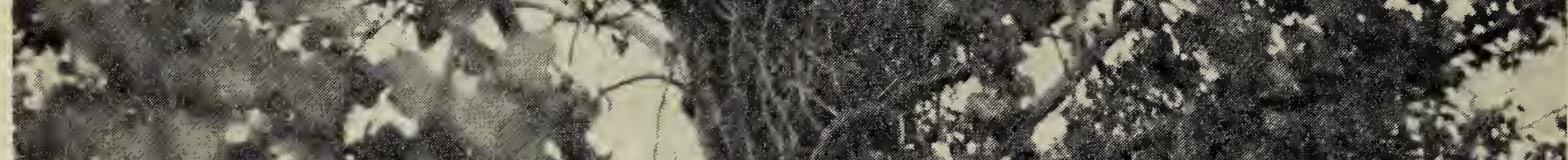

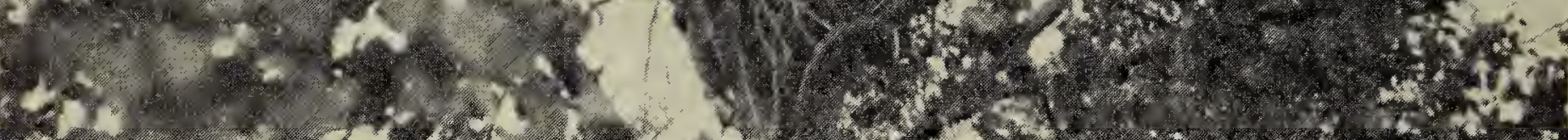

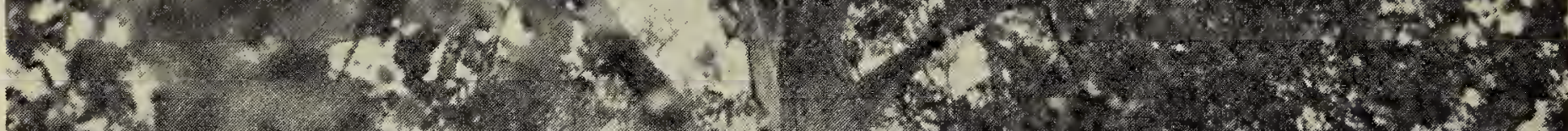

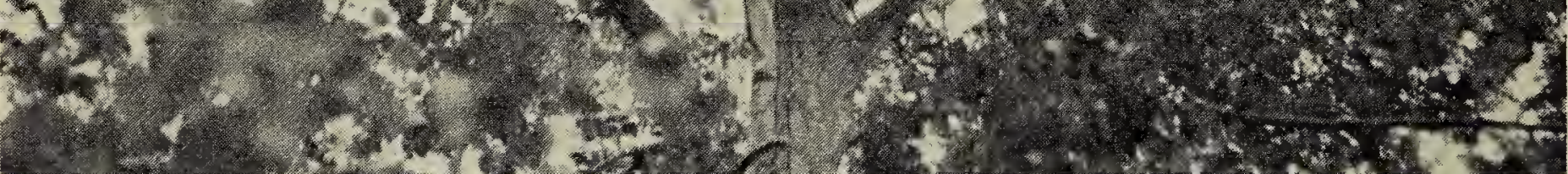

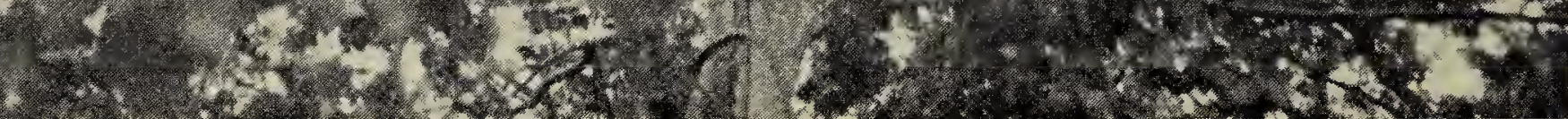
Figure 2. Kelwin Wylie banding eaglet Bruce Tomlinson

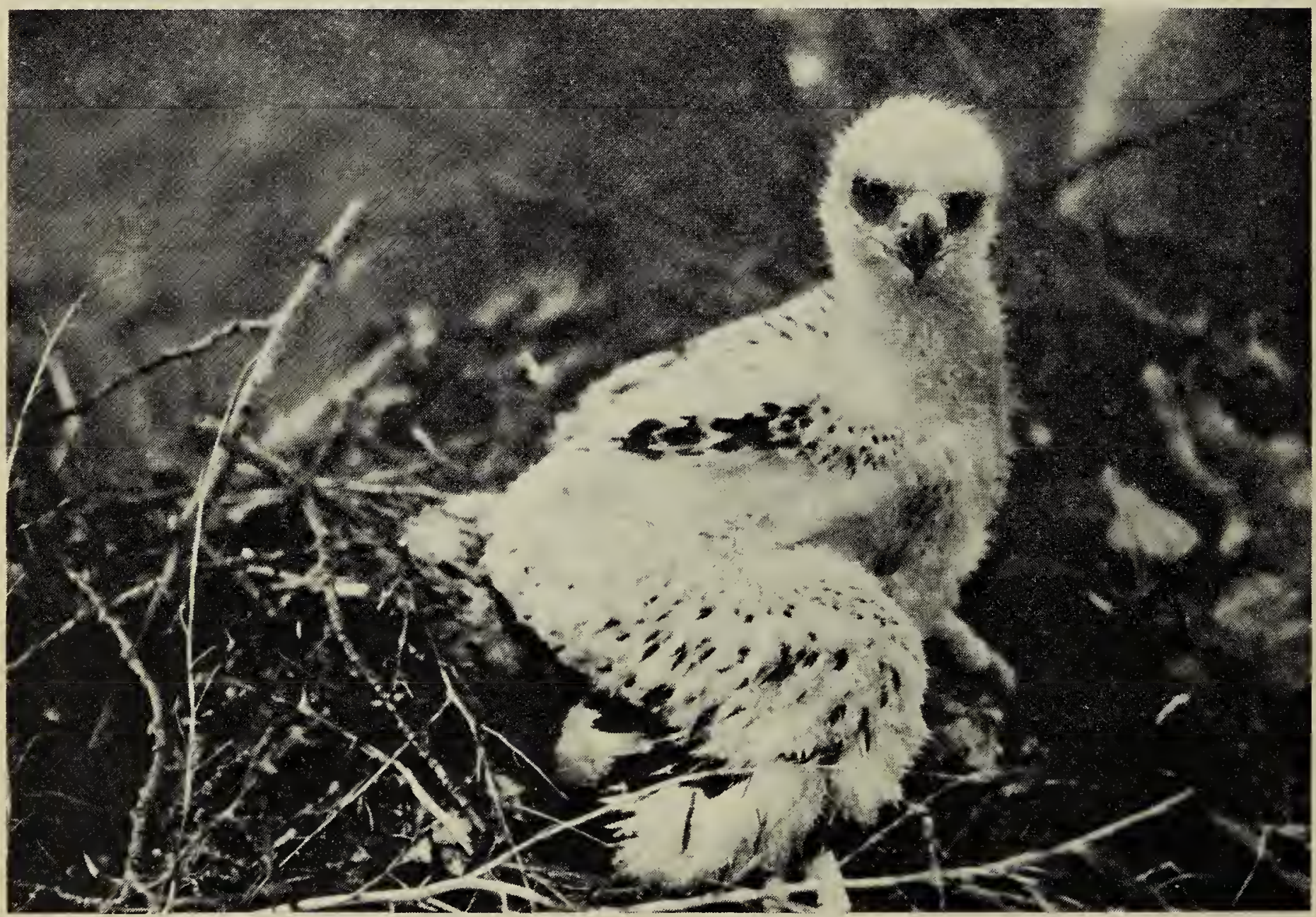

Figure 3. Young eaglet in nest

C.S. Houston 
